\title{
Green Drivers and Green Manufacturing Practices Integration in Agro Processing Industry: Moderating Effect of Sustainability Orientation
}

\author{
William Gyasi-Mensah* ${ }^{*} \quad$ Hu Xuhua \\ School of Finance and Economics, Jiangsu University, No. 301 Xuefu Rd., \\ Zhenjiang, Jiangsu, P.R.C. 212013 \\ E-mail of the corresponding author: gymmensah@yahoo.com
}

\begin{abstract}
Developing a balance between manufacturing and ecological preservation is considered a major issue in every society and so attention must be paid to this relationship to protect plant, animal and human lives. Pressure for manufacturing firms to become green has risen greatly. Green manufacturing has been encouraged, practiced and researched for years but mostly in developed nations, but low in developing countries. This is a follow up study on a previous one conducted by the authors on the direct effects of green drivers on green practices, and this current one aims at the moderating role of sustainability orientation on the effects of driving factors on green practices in Ghana. Analysis was done using structural equation modeling (SEM). Evidently, sustainability orientation (SUO) moderated significantly between driving factors and green design practices, green purchasing practices and green promotion/selling. Green design practices adoption was facilitated most by SUO. Green management practices and green logistics practices were not moderated by SUO. Outcomes of this work could serve as a guide towards decision making by industry actors and government of Ghana on policy formulation and better processes for integrating green practices, not just in the agro processing industry but all others with activities of possible damage to the environment.
\end{abstract}

Keywords: Green drivers, green practices, agro processing, sustainability orientation

DOI: $10.7176 / \mathrm{JESD} / 12-12-03$

Publication date:June $30^{\text {th }} 2021$

\section{Introduction}

Over the few recent years issues of environmental safety have become a subject of concern for policy makers and industry actors across the world. As result, manufacturing firms of all sizes across the globe and in all industries have been urged to apply initiatives that are friendly to the environment through adoption of certain practices. Adoption of green initiatives such as green manufacturing have gained enormous attention because, it is the expectation of policy makers it is one way minimizing or ending the dangerous effects of manufacturing activities while gaining benefits (Zhang and Fang, 2016). Of course as countries seek to industrialize, manufacturing cannot be underestimated for its benefits such as potential creation of employment and wealth (Thurner and Roud, 2016; Seth et al., 2018). Achieving any of these benefits can be challenging if policy makers and industry players fail to implement long term eco-friendly initiatives through methods such as green manufacturing (Wang and Sarkis, 2017; Moktadir et al., 2018). These approaches to green the manufacturing process can arise from activities aimed at resource reduction, minimizing waste and less generation of toxins into the environment. Aside the urge for firms to be environmentally sustainable while enjoying economic benefits, groups and organizations with interest in the environment have also been also been drawing attention for firms to be devoted towards eco-friendly approaches in their operations. Business enterprises of different sizes have recently facing compelling pressure from various stakeholders to integrate eco-friendly attitude in their businesses (Amankwah-Amoah and Syllias, 2019).

Green manufacturing is linked with the production processes that apply extensive eco-friendly materials and as well churn out higher products with minimized or no pollution from the manufacturing process (Baines et al. 2012; Dubey et al. 2015). Adoption of green manufacturing enables firms to reduce the consumption of raw materials, minimize energy consumption, minimize cost incurred from environmental and occupational hazards, as well as building a good corporate image in the eyes of the society (Porter and Van der Linde, 1995). Despite these advantages perceived to be gained from adopting and implementing green manufacturing practices, there are barriers that may hinder the smooth adoption and implementation of green phenomenon such as limited technology for implementing green manufacturing, insufficient funding for green adoption (Jabbour et al. 2016), resistance to change, reluctance to manufacturing disruption (Mittal et al. 2016). In the face of these benefits and challenges to adoption, it has become necessary to investigate what will drive firms to adopt the environmentally friendly methods of manufacturing especially in the developing world where many of these barriers are likely to be encountered. It is also necessary to ascertain the extent to which the orientation of firms on eco sustainability will affect its adoption and integration into their operations. 
The impact of SMEs in the economy of Ghana cannot be underestimated as they create huge amount of jobs and minimize post-harvest losses (Baumann-Pauly, et al., 2013, Hamann et al. 2017). According to AmpaduAmeyaw and Omari (2015), the agro processing industry performs a major function in through the creation of income and job opportunities in Ghana. The agro processing sub sector in Ghana comparatively exists as the sub sector of great importance in the manufacturing industry because they are in the middle of the agro food value chain, existing as a link between both producers and marketers in the industry.

Often times the environmental effects of manufacturing activities have been underrated especially among developing nations. However, since manufacturing has a direct effect on the environment, green the process cannot be underestimated and hence necessary. Whereas this issue of concern has been studied many time from developed and industrialized nation context, developing and less industrialized nations perspective is still new and under researched (Seth et al., 2016). Again, since many of studies on this subject have been in developed nations, applying their outcomes in developing nations like Ghana may be impossible. It is also not confirmed if these driving factors will drive firms to integrate green manufacturing practices fully or some other factors will facilitate this integration.

\section{Review and Hypotheses}

Among the motivations of a firm that uses conventional methods in its operation to develop and integrate ecofriendly methods in its processes is the awareness and commitment of management of the firm (Leonidou, et al, 2015). According to Christensen et al. (2014), the responsibility for developing aims, firm policies and organizational cultures that facilitate appropriate methods for adoption of eco-friendly practices lies on the managers or owners of the firm. In the opinion of Pinto and Allui (2016), driers that are internal to the firm exert higher effect on environmentally-friendly practices. Bahnot et al. (2017) supports this view with the assertion that, top management or owner commitment towards eco-friendly has been seen to be requirement without which integration of eco-friendly processes become a challenge. The critical importance of management or owner and staff commitment to green initiatives become even pronounced when their products are export oriented due to difference in political, legal and socio-cultural environments (Leonidou et al. 2015).

From the context of Resource-Base View (RBV), resources in relation with products are grounds for competitive edge for a firm (Barney, 2017). Modern definition puts it as the materials injected into the production processes such as skilled staff, know-how, financial capital, equipment and others (Kozlenkova et al. 2014). Firm resources may be considered as tangible such as equipment and financial capital or intangible such as experience and technical knowledge. These are inputs that enable the green agenda of the adopting firm (Lin and Wu, 2014). Theory suggests that, for resources to be well used in processes for success in the implementation of green practices to achieve its advantages, it ought not to be substitutable, not to be imitated, must be difficult to find and of high value (Vomberg et al. 2015, Cousins et al. 2019). In the opinion of (Leonidou et al.2016), firm resources play a vital role in environmental through for instance, making available a sound technological grounds to integrate environmentally friendly methods, finding new methods of green applications. Small enterprises mostly possess fewer resources, however those who have the few and use them strategically for ecologically friendly reasons, have a chance for high green performance (Klewitz and Hansen, 2014).

With the profiteering motive of every firm, the perceived benefit a firms expects to achieve from the integration of green practices motivates firms to adopt such practices. When a firms applies different methods to reduce waste, it is able to use less inputs for production, such as reducing packaging materials thereby, minimizing cost by the firm (Barzegar et al. (2018). Recycling of waste is one aspect of greening within en enterprise and this can help to cut down on excessive expenditure on new manufacturing inputs. Extant literature reveals that, a number of firms are not aware of the benefits of adopting green practices, such as saving on expenditure (Font et al. 2016; Yin et al., 2019), improved firm image (Park \& Kim, 2014; Aripin et al. 2018), higher profits (Bonini and Swartz, 2014; Wiesner et al., 2018). Value addition to products has a way of bringing in returns to the firm as suggested in (Prieto - Sandoval et al. 2019). Value chain theory context asserts that, bodies in the value chain that contributors in the value addition process at different stages adds some value to the product before it gets to the consumer who pays a fee for it (Mwirigi et al., 2016). The works of Bossle et al., (2016) and del Mar MirasRodriguez et al. (2018) have shown that, cost savings is one of the motivators for which firms choose to integrate eco-friendly processes in their activities. Despite these driving factor, Gandhi et al., (2018) in their study asserted that, it is not in all cases that, adoption of eco-friendly practices among SMEs should be seen as being a drain on firms but as a responsible manufacturing strategy.

As far as firm's attitude relating to ecological initiatives is concerned, past literatures have expressed the impact of consumer awareness on firm's decisions (Weng, et al., 2015). The expectations of consumers from manufacturers have has come to be one of the drivers of environmental responsibility among firms (Hsu, et al., 2013). A lot of consumers have developed intensive awareness on the environmental responsibility by firms and that; choose to purchase eco-friendly goods (Vilchez et al., 2017). Whether firms have been moved to go green by the green product demands of consumers is something that has been studied in previous studies. Again, from the 
context of supply chain past literature have shown that, regular pressure from players in the supply chain also coerce firms to become ecologically responsible supply chain initiatives (Wolf, 2013; Zhang et al. 2018). In order for firms to keep their customers, they are forced to pay attention to the feedbacks of their customers to gain. Their increased environmental concerns compel businesses to be eco-friendly in their business operations (Weng et al. 2015). Customers who purchase from overseas markets may require reliable signs such as ISO 14001 indicating the commitment of product manufacturers towards safe environment (Testa et al., 2018), thus affecting strategies of firms towards environmental protection.

Businesses do not operate in isolation and thus, operate with other competing firms in the same industry. When one firm adopts new environmental initiative, competitors are likely to feel pressured to re-assess their own processes concerning eco responsibility and conclude whether to make changes to their environmental initiatives (Marano and Kostova, 2016). In several business environments where businesses exist, there is some amount of pressure from competing companies in the industry that moves other businesses to accept and integrate ecofriendly practices with the aim of surviving in the industry (Ogunlela, 2018). Continuous influence from competitors force firms to implement environmentally safe initiatives such as eco-design not in the product design phase only, but also in their role as actors in the supply chain (Tamayo-Orbegozo et al. 2017).

From institutional theory context, the pressure from competitors on the firms to adopt certain green initiatives is referred to as mimetic (Tachizawa et al. 2015). This form of influence is seen at the times that enterprises imitate that activities of their competing enterprises when they observe them and realize the successes of those initiatives, they tend to copy these in order to gain positive image and survive in the industry (Govindan, 2018). To continue to enjoy advantages in the market, firms may resort to doing what competitors are doing and even better concerning environmental initiatives (Galeazzo and Klassen, 2015; Dangelico, 2016). Regulations regarding the environment and its adherence as a driving factor present some form of legal confines within which enterprises need to operate for environmental sustainability in their operations. Several researches have delved into the link between state regulations and environmental initiatives and have opined that, governmental pressure or influence through environmental regulations remains one major driver of green manufacturing initiatives adoption (Wolf, 2013; Dixon-Fowler et al. 2017). Regulations and its strict adherence by the state through agencies and bodies influence the activities of firms on environmental management (Hsu et al. 2013; Lin et al. 2014) and thereby stay in business. Again, to be competitive in the global market space, firms may have to adhere to both global and local regulations aimed at preserving the environment. From the context of institutional theory, the compulsion from regulations on firms to be environmentally responsible is referred to as coercive isomorphism aimed at making a firm engage in green initiatives. According to Thaib (2020), for a firm to adopt and integrate environmental management initiatives, such as eco-design, reverse logistics and others, it requires some amount of coercive pressure. In the opinion of Wang et al. (2019), the extent to which regulations are enforced in industrialized nations erupt some level of institutional pressure for enterprises in developing countries towards improving their responsible practices towards the environment. In the nutshell, support from the state and compliance to regulations is seen to influence greatly the policies and implementation of environmentally benign initiatives (Singh et al., 2014; He et al., 2016).

Sustainability orientation (SUO) refers to the overall proactive strategic stance of small firms towards the integration of natural environmental concerns in their business operations. Firms with higher levels of SUO are likely to have institutionalized in its overall strategy, structure, processes and activities a wide range of measures designed to either reduce the firm's negative impact on the natural environment or to positively contribute to environmental protection, preservation or re-generation. Recently, sustainability researchers have demonstrated that a firm's sustainability orientation is deeply rooted in values and beliefs that provide behavioural norms that trigger or shape its sustainability activities and, thus, enhance employee behaviours in new product development activities (Claudy et al. 2016; Varadarjan 2017). It may be described as intrinsic values and ethical standards of company commitment towards environmental protection (Chen et al. 2015). Sustainability orientation accordingly has an impact on the integration of the new product design and processes into the organizational structure (Klewitz and Hansen, 2014).

Moreover, sustainability orientation positively affects the practices included in firm's sustainability strategies (Kirchoff, et al., 2016) and actively influences firm behaviour in practice (Johnson, 2015). Sustainability orientation is typically reflected on the redesign of firms' products and production processes through green adoption according to the environmental and social regulations that ultimately generate competitive advantage (Aikenhead et al., 2015). The business enterprise is perceived to possess enormous degree of orientation and commitment towards environmental responsibility when they decide to implement ecologically safe manufacturing activities motivated by an enterprise-wide feeling of responsibility and accountability for the potential effect of the activities of the business enterprise on the environment (Roxas et al. 2017). Considered as a firm-level strategic orientation, sustainability orientation ought to be ingrained in the grand business philosophy of the business and become part of the overall strategic configurations which directs the business or operational plans, programs and practices of the firm (Carroll, 1979). Through several ways, firms demonstrate their sustainability orientation, such as pollution prevention or minimization (Kraus et al. 2018), investment in eco- 
friendly technologies (Torkkeli et al. 2017). A study posits that adoption of green activities in an organization differs between large and small firms given the difference in their characteristics (Tyler et al. 2018). Therefore, the current research seeks to investigate how sustainability orientation mediates or facilitate the adoption of green manufacturing initiatives among small and medium agro processing firms in Ghanaian business environment. We propose that:

H1a: Sustainability orientation significantly moderates the adoption of: Green management practices

H1b: Sustainability orientation significantly moderates the adoption of: Green design practices

H1c: Sustainability orientation significantly moderates the adoption of: Green purchasing practices

H1d: Sustainability orientation significantly moderates the adoption of: Green promotion/selling

H1e: Sustainability orientation significantly moderates the adoption of: Green logistics practices. Driving Factors

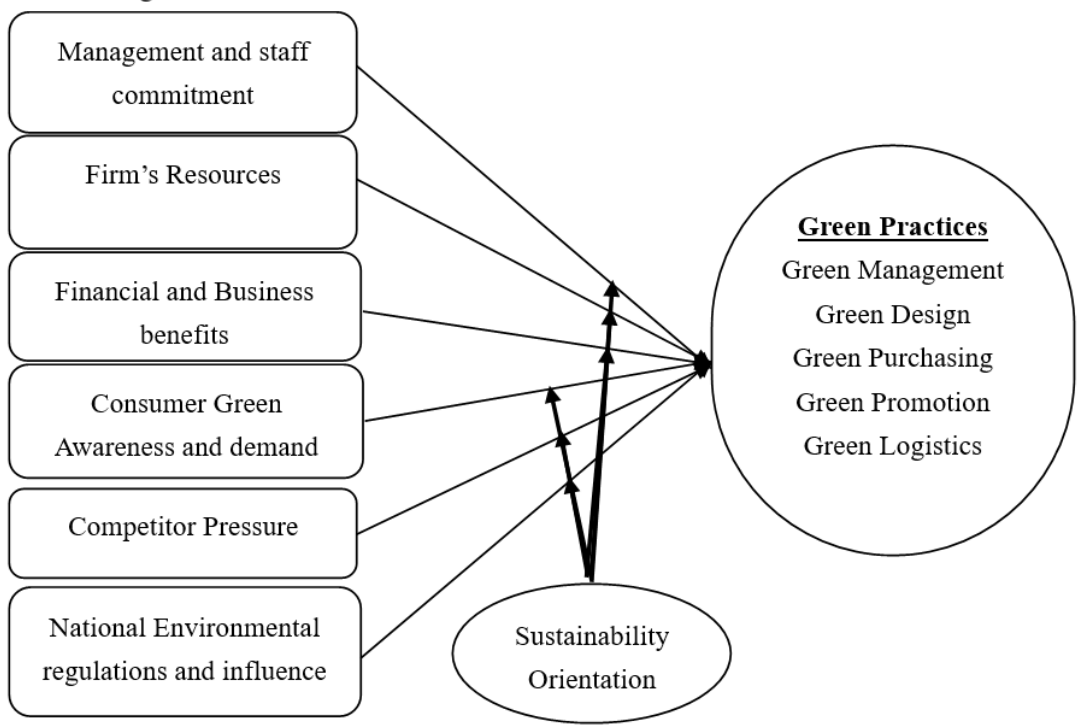

Figure 1. The research framework

\section{Methods}

\subsection{Sample choice and characteristics}

The agro processing sector of the manufacturing industry was chosen as the population. The reasons as assigned are two folds. Firstly, few studies have been conducted on other industries and sectors such as green orientation, customer based brand equity and competitive advantage in Ghana (Amegbe and Hanu, 2016), reverse logistics practices in Ghana's pharmaceutical industry (Kwarteng et al. 2014), but less attention has been paid to the agro processing industry which is a major contributor to Ghana's economy. Secondly, this industry is mostly dominated by small and medium enterprises on which this investigation is based, thus making it the appropriate choice of industry for this study.

\subsection{Instrument design}

In order to solicit the responses of our sample size firms, a survey was conducted using a set of questionnaire to investigate the proposed framework. Premised on review of past studies, the researcher designed a structured questionnaire with seven constructs to measure how the sampled firms find sustainability orientation to moderate or facilitate between the driving factors and their adoption of green manufacturing initiatives. With the aim of getting more precise data from respondents in this study, a pilot study was conducted among 50 SMEs observe the understanding of the concept, as well as to notice any ambiguities and suggest improvements to the survey questions. A close look at the feedback resulted in reassessment and finally the set of questionnaire was developed. The various constructs were measured on a five-point likert scale ( $1=$ strongly disagree to $5=$ strongly agree $)$.

\subsection{Data collection}

This study was premised on green manufacturing practices and the factors that drive its adoption among agro processing SMEs in Ghana. Targeted respondents to the set questionnaire were manufacturing managers or supervisors of sampled firms. The reason is that, they are personnel in these firms who are seen to be closer to the processes involved in the production process and likely to be privy to any new initiatives implemented in the manufacturing process. One peculiar feature of SMEs is that, they are usually owned and managed by one or two people who make all decisions concerning the firm (Wiltshire Committee, 1971) and have thorough knowledge of the firm's practices and strategies. To avoid ambiguity in our results, a pre-test exercise comprising 60 firms was 
carried out to assess first-hand the relationship between our independent and dependent constructs. No discrepancies of high magnitude were observed at the 0.05 significance level after all questionnaires were received; hence biases in responses were not seen as obstacle. To encourage committed participation, the researchers presented green manufacturing branded souvenirs to each respondent. Also, respondents were given the fullest assurance of their responses being used for research purposes only. In all 415 SMEs in Eastern, Greater Accra and Ashanti territories of Ghana were the locations for sampling because they shared similar features of our target firms.

\subsection{Analysis approach}

This study is a follow up study to the work of Gyasi-Mensah and $\mathrm{Hu}$ (2019) and so a similar analysis approach was adopted, using structural equation modelling with AMOS 24.0 to test the moderating effect of sustainable orientation. All procedures in Gyasi-Mensah and $\mathrm{Hu}$ (2019) were followed and then the mediating effect of sustainability orientation was also analyzed. In addition to the approach followed in the initial study in which the relationship between independent variables comprising MSC, FBB, FRS, CAD, CIP and NEI with their constructs were analyzed as first order factors (ee1-ee22), with dependent variables comprising GMP, GDP, GPP, GPS and GLP as second order factors (ee23-ee40), the moderating variable represented by sustainable orientation which is denoted by 'SUO' in the subsequent parts of this study, and its' effect was also analyzed. Together they measured the relationship among the latent variables as seen in the research framework.

\section{Results}

\subsection{Descriptive statistics}

Table 1. Descriptive statistics showing category, frequency and percentages of descriptive items

\begin{tabular}{|c|c|c|c|c|}
\hline Number & Variable & Category & Frequency & $\begin{array}{l}\text { Percent } \\
(\%)\end{array}$ \\
\hline \multirow[t]{3}{*}{1} & \multirow{3}{*}{$\begin{array}{l}\text { Years of Operation } \\
(\mathrm{N}=415)\end{array}$} & $<10$ & 108 & $26.0 \%$ \\
\hline & & $10-20$ & 174 & $41.9 \%$ \\
\hline & & $>20$ & 133 & $32.0 \%$ \\
\hline \multirow[t]{2}{*}{2} & \multirow{2}{*}{$\begin{array}{l}\text { Environmental management body registration } \\
\text { Status }(\mathrm{N}=415)\end{array}$} & Registered & 275 & $66.3 \%$ \\
\hline & & Unregistered & 140 & $33.7 \%$ \\
\hline \multirow[t]{2}{*}{3} & \multirow[t]{2}{*}{ Environmental management unit $(\mathrm{N}=415)$} & Have & 279 & $67.2 \%$ \\
\hline & & Do not Have & 136 & $32.8 \%$ \\
\hline \multirow[t]{2}{*}{4} & \multirow[t]{2}{*}{ Environmental management policy $(\mathrm{N}=415)$} & Have & 263 & $63.4 \%$ \\
\hline & & Do not Have & 152 & $36.6 \%$ \\
\hline
\end{tabular}

Table 1 above expresses the description and characteristics of the various samples that were used in this study in relation to their environmental responsibility and management.

In Table 2, the outcome of factor analysis is presented. Reliability and validity of data used in this study were obtained using Cronbach alpha and average variance extracted (AVE) respectively. The figures representing all individual models recorded above 0.7 , indicating a firm and approved reliability for the scale used, in consonance with the techniques of Hair Jr. et al., (2014). On validity, the results showed that all figures of AVE were greater than the standard value of 0.5 , hence making al variables valid for analysis (Hair et al. (2014).

Table 2. Factor analysis of construct items, factor loadings, AVE and Cronbach's alpha values for variables

\begin{tabular}{|l|l|l|l|}
\hline Variable & Factor Loading & AVE & Cronbach's Alpha \\
\hline Management and Staff's GM Commitment (MSC) & 0.682 & 0.840 \\
\hline MSC1 & 0.860 & & \\
\hline MSC2 & 0.816 & & \\
\hline MSC3 & 0.716 & & \\
\hline MSC4 & 0.639 & & \\
\hline Financial and Business Benefits (FBB) & 0.646 & 0.724 \\
\hline FBB1 & 0.754 & & \\
\hline FBB2 & 0.651 & & \\
\hline FBB3 & 0.651 & 0.667 & 0.749 \\
\hline Firm's Resources (FRS) & & \\
\hline FRS1 & 0.803 & & \\
\hline FRS2 & 0.680 & & \\
\hline FRS3 & 0.644 & 0.550 & 0.781 \\
\hline Consumer awareness and demand (CAD) & & \\
\hline CAD1 & 0.749 & & \\
\hline CAD2 & 0.699 & & \\
\hline
\end{tabular}




\begin{tabular}{|c|c|c|c|}
\hline Variable & Factor Loading & AVE & Cronbach's Alpha \\
\hline CAD3 & 0.686 & & \\
\hline CAD4 & 0.589 & & \\
\hline CAD5 & 0.582 & & \\
\hline \multicolumn{4}{|c|}{ Competitor influence or pressure (CIP) } \\
\hline CIP1 & 0.815 & 0.679 & 0.761 \\
\hline CIP2 & 0.714 & & \\
\hline CIP3 & 0.634 & & \\
\hline \multicolumn{4}{|c|}{ National environmental regulations and Civil Society Groups' influence (NEI) } \\
\hline NEI1 & 0.755 & 0.585 & 0.763 \\
\hline NEI2 & 0.695 & & \\
\hline NEI3 & 0.659 & & \\
\hline NEI4 & 0.562 & & \\
\hline \multicolumn{4}{|c|}{ Green Management (GMP) } \\
\hline GMP1 & 0.632 & 0.505 & 0.772 \\
\hline GMP2 & 0.577 & & \\
\hline GMP3 & 0.569 & & \\
\hline GMP4 & 0.554 & & \\
\hline \multicolumn{4}{|c|}{ Green Design Practices (GDP) } \\
\hline GDP1 & 0.853 & 0.588 & 0.767 \\
\hline GDP2 & 0.677 & & \\
\hline GDP3 & 0.586 & & \\
\hline GDP4 & 0.568 & & \\
\hline \multicolumn{4}{|c|}{ Green Purchasing (GPP) } \\
\hline GPP1 & 0.762 & 0.599 & 0.788 \\
\hline GPP2 & 0.634 & & \\
\hline GPP3 & 0.506 & & \\
\hline \multicolumn{4}{|c|}{ Green Promotion/Selling } \\
\hline GPS1 & 0.871 & 0.650 & 0.811 \\
\hline GPS2 & 0.803 & & \\
\hline GPS3 & 0.790 & & \\
\hline \multicolumn{4}{|c|}{ Green Logistics Practices (GLP) } \\
\hline GLP1 & 0.811 & 0.637 & 0.810 \\
\hline GLP2 & 0.637 & & \\
\hline GLP3 & 0.628 & & \\
\hline GLP4 & 0.593 & & \\
\hline
\end{tabular}

\subsection{Analysis}

Table 3. Results of moderating effect of sustainability orientation on green practices

\begin{tabular}{|l|l|l|l|l|l|l|l|}
\hline \multicolumn{2}{|c|}{ Path of influence } & Estimate & S.E. & C.R. & P & Supported \\
\hline GMP & $<---$ & SUO & 0.051 & 0.066 & 0.77 & 0.442 & No \\
\hline GDP & $<---$ & SUO & 0.15 & 0.068 & 2.226 & 0.026 & Yes \\
\hline GPP & $<---$ & SUO & 0.115 & 0.055 & 2.1 & 0.036 & Yes \\
\hline GPS & $<---$ & SUO & 0.091 & 0.042 & 2.182 & 0.029 & Yes \\
\hline GLP & $<---$ & SUO & 0.094 & 0.08 & 1.173 & 0.241 & No \\
\hline
\end{tabular}

It is worth reminding that, this study is a follow up study to Gyasi-Mensah and $\mathrm{Hu}(2019)$ and for that matter, there may be reference to that study when necessary. Therefore in this analysis, results on the non significant direct relationship between driving factors and green practices adoption only will be compared after introducing the moderation variable of SUO. In reference to our previous work (Gyasi-Mensah and Hu, 2019), we realized that, the direct relationship between the drivers and green practices had statistically non significant $\mathrm{p}$ values as follows (MSC-->GMP, 0.548), (CAD-->GMP, 0.848) and (FRS--> GMP, 0.949). The rest being FBB, CIP and NEI had statistically significant relationship with GMP. From table 2, it was observed that, SUO had a statistically non significant relationship with green management practices which from now will be represented by GMP with pvalue of 0.442 at 0.05 significant levels. This implies that, the moderating effect of GMP between the non significant independent variable and the green practices could not be validated, hence H1a was not supported.

The direct relationship between FRS--> GDP and CAD-->GDP were statistically non significant with p-values of 0.708 and 0.497 respectively. The remaining drivers all recorded statistically significant relationships with GDP. 
The statistically significant connection between SUO and green design practices (denoted by GDP) was seen to be statistically significant with p-value of 0.026 at 0.05 significant levels. This validated the significant moderating role of SUO. Hence, our hypothesis $1 \mathrm{~b}$ was supported.

On the part of GPP, the direct correlation between MSC-->GPP, FRS-->GPP, CAD-->GPP, CIP-->GPP were all statistically non significant with p-values of $0.076,0.407,0.197$ and 0.19 respectively. All other driving factors had a significant relationship with GPP. A statistically significant relation existed between SUO and GPP with 0.036 at 0.05 significant levels, thereby suggesting a significant moderating role of SUO towards adoption of GPP. Thus, H1c was supported.

Concerning GPS and the independent variables from direct relationship context, we observed that, there was statistically non significant relationship between MSC-->GPS, FRS-->GPS, CAD-->GPS and NEI-->GPS with pvalues of $0.282,0.913,0.611$ and 0.213 respectively. On the other hand, FBB and CIP had significant relationship with GPS. Our results showed a significant correlation between SUO and GPS with a p-value of 0.029 at 0.05 significant levels, thus showing that, a firm's SUO will improve adoption of green promotion practice, when driven by especially the factors with non significant relationship. Thus H1d was supported.

From our results, it was realized that directly, the relationship between the driving factors and GLP, that is, MSC-->GLP, FRS-->GLP, and CAD --> GLP were not significant statistically as they recorded p-values of 0.109 , 0.074 and 0.43 respectively at 0.05 significance levels. However, FBB, CIP and NEI statistically correlated significantly with GLP at 0.05 significance levels. From table 2 above, it evident that the moderating relationship between SUO and GLP was statistically non significant with p-value of 0.241 at 0.05 significance levels, thus invalidating a possible capacity to improve the effect of the independent variable factors on GLP and its integration in the agro processing industry. This implies H1e failed to be supported.

\subsection{Discussion}

This study exhibits that sustainability orientation generally has effect on the acceptance and integration in the business operations of SMEs in the agro processing industry in Ghana. The present study widens the discussion and for that matter literature on the drivers of eco friendly manufacturing and green practices adoption, especially in the developing world. We developed a framework to test the mediating effect of sustainability orientation on green practices within agro processing SMEs in Ghana. Having summarized the results of the direct effect of green drivers on green practices adoption as in Gyasi-Mensah and Hu (2019), we proceed to discuss the moderating role of sustainability orientation between green drivers and green practices.

The findings in this study shows that SUO could not establish a good relationship between green driving factors and green practices. However, this assertion contradicts the findings of Kirchoff et al. (2016) who found a positive relationship between SUO and green management. Again, the study of Yu and Huo (2019) shows that, sustainability orientation has a significant impact, and thus facilitates green management practices especially in relations to supplier. The reason for this disagreement between the current and previous studies could be that, most of these firms are driven by external factors directly than by internal factors (Gyasi-Mensah and Hu, 2019).

Our results showed that there exist a positive relationship between SUO and green design practice. In other words, with a strong SUO, firms are greatly driven toward green design practices in the SME industry. This is consistent with the findings of Shashi, Cerchione, Centobelli and Shabani (2018) who suggested that, SUO will lead to green or sustainable design in SMEs. It is again supported by the findings of Feng et al. (2018) which concluded that, internal and external sustainability orientation positively affects the green product and process developments which are offshoots of green design practices. Thus, the moderating effect of SUO between drivers and green practices is validated.

The outcome of this study which is supported by a dataset comprising 415 Ghanaian SMEs, expressed that, SUO is very vital phenomenon towards the green practices of the agro processing industry, specifically green purchasing. In congruence with the findings of Shashi et al. (2018), our findings posit that SUO will highly lead to green purchasing among SMEs in the industry under consideration in this study. Therefore, it is necessary for SUO to be encouraged in the industry for improved green effect. Our results are also in consonance with the findings of Ghosh (2019) which posited that, firms that pay attention to environmental concerns or have environmental orientation are very well leaned towards green purchasing practices in their operations.

On the green promotion/selling practice, sometimes referred to green marketing, our results found a favourable relationship between SUO and GPS, thus confirming a significant moderating role for SUO. Our findings are supported by previous work of Joshi and Rahman (2019). Their work expressed that environmental concerns was a major driver of green purchasing of products in SMEs. Alabdali (2019) considered the change in senior management's stance towards implementing green initiatives as an emergence of orientation on greening the product marketing process and thus posits that, the manager or supervisor's SUO affects GPS implementation. However, this is in disagreement with the findings of Adawiyah (2018) who found that environmental consciousness does not have significant impact on effective GPS in SMEs, in that government in Indonesia fails to pressurize firms to be ecologically responsible. 
Green logistics as well as reverse logistics form an integral part of green supply chain and for that matter considered in many studies from the context of green supply chain. The findings of Chu (2016) indicated that, internal and external sustainability orientation had a positive relationship with green supply chain (logistics). Again Marshall et al. (2015) described sustainability orientation as sustainability culture and asserted a positive relationship between sustainability culture (SUO) and green supply chain practice. However, our findings showed that SUO could not significantly relate with green logistics practices. In other words, the moderating effect of SUO in this study could not be validated. A possible reason could be the lack of enforced regulations and the absence of penalty or punishments when firms ignore the negative footprints of products on the environment throughout the supply or distribution process.

\section{Conclusion}

Green practices integration in business operations are seen as a major boost towards environmental preservation. By implementing these initiatives within forms and the industry as a whole, manufacturing SMEs can reduce their negative impacts on the environment, whilst reaping the accompanying benefits. The motive of manufacturing firms is to meet the demands of their consumers while making profit, but their effect on society cannot be ignored. It is for this reason that, studies are continuously being conducted on how their activities can be made as sustainable as possible and this study is no exception. This study has extended the debate on what among many other factors will be necessary for SMEs to go green through adoption of certain practices. It has presented and verified the specific green practices among those being applied in this study whose adoption is well moderated by sustainability orientation. In effect, the researchers believe that, further research may be required to further ascertain why the other practices could not be mediated by sustainability orientation.

\section{References}

Adawiyah, W.R., 2017. Determinants of Green Marketing Quality Practices among Small Medium Enterprises (Smes). EKUITAS (Jurnal Ekonomi dan Keuangan), 1(2), pp.240-258.

Aikenhead, G., Farahbakhsh, K., Halbe, J. and Adamowski, J., 2015. Application of process mapping and causal loop diagramming to enhance engagement in pollution prevention in small to medium size enterprises: case study of a dairy processing facility. Journal of Cleaner Production, 102, pp.275-284.

Alabdali, N.H., 2019. Factors affecting the application of the concept of Green Marketing: An Empirical Study in Saudi Food Industry Companies. International Journal of Business and Social Science, 10(6), pp. 43-53

Amankwah-Amoah, J. and Syllias, J., 2020. Can adopting ambitious environmental sustainability initiatives lead to business failures? An analytical framework. Business Strategy and the Environment, 29(1), pp.240-249.

Amegbe, H. and Hanu, C., 2016. Exploring the Relationship Between Green Orientation, Customer Based Brand Equity (CBBE) and the Competitive Performance of SMEs in Ghana. Journal of Marketing Development \& Competitiveness, 10(1), pp. 80-93

Ampadu-Ameyaw, R. and Omari, R., 2015. Small-scale rural agro-processing enterprises in Ghana: Status, challenges and livelihood opportunities of women. Journal of Scientific Research and Reports, 6(1), pp.6172.

Aripin, N., Amran, N.A., Saad, N. and Awaluddin, N.R., 2018. Green practices in the hotel industry: the push and pull factors. International Journal of Supply Chain Management (IJSCM), 7(6), pp.158-164.

Baines, T., Brown, S., Benedettini, O. and Ball, P., 2012. Examining green production and its role within the competitive strategy of manufacturers. Journal of Industrial Engineering and Management (JIEM), 5(1), pp.53-87.

Barney, J.B., 2017. Resources, capabilities, core competencies, invisible assets, and knowledge assets: Label proliferation and theory development in the field of strategic management. The SMS Blackwell handbook of organizational capabilities, pp.422-426.

Barzegar, M., Ehtesham Rasi, R. and Niknamfar, A.H., 2018. Analyzing the drivers of green manufacturing using an analytic network process method: a case study. International journal of research in industrial engineering, 7(1), pp.61-83.

Baumann-Pauly, D., Wickert, C., Spence, L.J. and Scherer, A.G., 2013. Organizing corporate social responsibility in small and large firms: Size matters. Journal of business ethics, 115(4), pp.693-705.

Bhanot, N., Rao, P.V. and Deshmukh, S.G., 2017. An integrated approach for analysing the enablers and barriers of sustainable manufacturing. Journal of cleaner production, 142, pp.4412-4439.

Bonini, S. and Swartz, S., 2014. Profits with purpose: How organizing for sustainability can benefit the bottom line. McKinsey on Sustainability \& Resource Productivity, 2, pp.1-15.

Bossle, M.B., de Barcellos, M.D., Vieira, L.M. and Sauvée, L., 2016. The drivers for adoption of ecoinnovation. Journal of Cleaner production, 113, pp.861-872.

Carroll, A.B., 1979. A three-dimensional conceptual model of corporate performance.

Academy of management review, 4(4), pp.497-505. 
Chen, Y., Tang, G., Jin, J., Li, J. and Paillé, P., 2015. Linking market orientation and environmental performance: The influence of environmental strategy, employee's environmental involvement, and environmental product quality. Journal of Business Ethics, 127(2), pp.479-500.

Chu, K.M., 2016. The Role of a strategic and sustainable orientation in green supply chain management. International Journal of Sustainable Entrepreneurship and Corporate Social Responsibility (IJSECSR), 1(2), pp.40-61.

Claudy, M.C., Peterson, M. and Pagell, M., 2016. The roles of sustainability orientation and market knowledge competence in new product development success. Journal of Product Innovation Management, 33, pp.72-85.

Cousins, P.D., Lawson, B., Petersen, K.J. and Fugate, B., 2019. Investigating green supply chain management practices and performance. International Journal of Operations \& Production Management, 39(5). pp.767786

Dangelico, R.M., 2016. Green product innovation: Where we are and where we are going. Business Strategy and the Environment, 25(8), pp.560-576.

del Mar Miras-Rodriguez, M., Machuca, J.A. and Escobar-Pérez, B., 2018. Drivers that encourage environmental practices in manufacturing plants: A comparison of cultural environments. Journal of Cleaner Production, 179, pp.690-703.

Dixon-Fowler, H.R., Ellstrand, A.E. and Johnson, J.L., 2017. The role of board environmental committees in corporate environmental performance. Journal of Business Ethics, 140(3), pp.423-438.

Dubey, R., Gunasekaran, A. and Ali, S.S., 2015. Exploring the relationship between leadership, operational practices, institutional pressures and environmental performance: A framework for green supply chain. International Journal of Production Economics, 160, pp.120-132.

Feng, L., Zhao, W., Li, H. and Song, Y., 2018. The Effect of Environmental Orientation on Green Innovation: Do Political Ties Matter?. Sustainability, 10(12), p.4674.

Font, X., Garay, L. and Jones, S., 2016. Sustainability motivations and practices in small tourism enterprises in European protected areas. Journal of Cleaner production, 137, pp.1439-1448.

Galeazzo, A. and Klassen, R.D., 2015. Organizational context and the implementation of environmental and social practices: what are the linkages to manufacturing strategy?. Journal of Cleaner Production, 108, pp.158-168.

Gandhi, N.S., Thanki, S.J. and Thakkar, J.J., 2018. Ranking of drivers for integrated lean-green manufacturing for Indian manufacturing SMEs. Journal of Cleaner Production, 171, pp.675-689.

Ghosh, M., 2019. Determinants of green procurement implementation and its impact on firm performance. Journal of Manufacturing Technology Management, 30(2), pp.462-482

Govindan, K., 2018. Sustainable consumption and production in the food supply chain: A conceptual framework. International Journal of Production Economics, 195, pp.419-431.

Gyasi-Mensah, W. \& Hu, X. (2019). Green Manufacturing in Agro Processing SMEs: Unraveling the Relationship Between Drivers and Their Effects on Adoption Practices in Ghana. International Journal of Global Sustainability, 3(1), pp.136-164

Hair Jr, J.F., Sarstedt, M., Hopkins, L. and Kuppelwieser, V.G., 2014. Partial least squares structural equation modeling (PLS-SEM): An emerging tool in business research. European business review. 26(2), pp.106-121

Hamann, R., Smith, J., Tashman, P. and Marshall, R.S., 2017. Why do SMEs go green? An analysis of wine firms in South Africa. Business \& Society, 56(1), pp.23-56.

He, Z.X., Xu, S.C., Shen, W.X., Long, R.Y. and Chen, H., 2016. Factors that influence corporate environmental behavior: Empirical analysis based on panel data in China. Journal of Cleaner Production, 133, pp.531-543.

Hsu, C.C., Tan, K.C., Zailani, S.H.M. and Jayaraman, V., 2013. Supply chain drivers that foster the development of green initiatives in an emerging economy. International Journal of Operations \& Production Management, 33(6), pp.656-688

Jabbour, C.J.C., de Sousa Jabbour, A.B.L., Govindan, K., De Freitas, T.P., Soubihia, D.F., Kannan, D. and Latan, H., 2016. Barriers to the adoption of green operational practices at Brazilian companies: effects on green and operational performance. International journal of production research, 54(10), pp.3042-3058.

Johnson, M.P., 2015. Sustainability management and small and medium - sized enterprises: Managers' awareness and implementation of innovative tools. Corporate Social Responsibility and Environmental Management, 22(5), pp.271-285.

Jones Christensen, L.I.S.A., Mackey, A. and Whetten, D., 2014. Taking responsibility for corporate social responsibility: The role of leaders in creating, implementing, sustaining, or avoiding socially responsible firm behaviors. Academy of Management Perspectives, 28(2), pp.164-178.

Joshi, Y. and Rahman, Z., 2015. Factors affecting green purchase behaviour and future research directions. International Strategic management review, 3(1-2), pp.128-143.

Kirchoff, J.F., Tate, W.L. and Mollenkopf, D.A., 2016. The impact of strategic organizational orientations on green supply chain management and firm performance. International Journal of Physical Distribution \& Logistics Management, 46(3), pp.269-292 
Klewitz, J. and Hansen, E.G., 2014. Sustainability-oriented innovation of SMEs: a systematic review. Journal of cleaner production, 65 , pp.57-75.

Kozlenkova, I.V., Samaha, S.A. and Palmatier, R.W., 2014. Resource-based theory in marketing. Journal of the Academy of Marketing Science, 42(1), pp.1-21.

Kraus, S., Burtscher, J., Vallaster, C. and Angerer, M., 2018. Sustainable entrepreneurship orientation: A reflection on status-quo research on factors facilitating responsible managerial practices. Sustainability, 10(2), p.444.

Kwarteng, A., Dadzie, S.A. and Famiyeh, S., 2016. Sustainability and competitive advantage from a developing economy. Journal of Global Responsibility, 7(1), pp.110-125

Leonidou, L.C., Christodoulides, P. and Thwaites, D., 2016. External determinants and financial outcomes of an eco - friendly orientation in smaller manufacturing firms. Journal of Small Business Management, 54(1), pp.5-25.

Leonidou, L.C., Fotiadis, T.A., Christodoulides, P., Spyropoulou, S. and Katsikeas, C.S., 2015. Environmentally friendly export business strategy: Its determinants and effects on competitive advantage and performance. International Business Review, 24(5), pp.798-811.

Lin, H., Zeng, S.X., Ma, H.Y., Qi, G.Y. and Tam, V.W., 2014. Can political capital drive corporate green innovation? Lessons from China. Journal of cleaner production, 64, pp.63-72.

Marano, V. and Kostova, T., 2016. Unpacking the institutional complexity in adoption of CSR practices in multinational enterprises. Journal of Management Studies, 53(1), pp.28-54.

Marshall, D., McCarthy, L., McGrath, P. and Claudy, M., 2015. Going above and beyond: how sustainability culture and entrepreneurial orientation drive social sustainability supply chain practice adoption. Supply Chain Management: An International Journal, 20(4), pp.434-454

Mittal, V.K., Sindhwani, R. and Kapur, P.K., 2016. Two-way assessment of barriers to lean-green manufacturing system: insights from India. International Journal of System Assurance Engineering and Management, 7(4), pp.400-407.

Moktadir, M.A., Rahman, T., Rahman, M.H., Ali, S.M. and Paul, S.K., 2018. Drivers to sustainable manufacturing practices and circular economy: A perspective of leather industries in Bangladesh. Journal of Cleaner Production, 174, pp.1366-1380.

Ogunlela, G.O., 2018. Green supply chain management as a competitive tool in the fast-moving consumer goods manufacturing industry. Journal of Business and Retail Management Research, 12(4). pp. 167-176.

Mwirigi, P.M., Namusonge, G.. \& Mwita, P., 2016. Influence of Perceived Business Benefits on Adoption of Green Supply Chain Strategy by Manufacturing Firms in Kenya. International Journal of Innovative Research \& Development, 5(4), pp.356-366

Park, J., Jeong Kim, H. and McCleary, K.W., 2014. The impact of top management's environmental attitudes on hotel companies' environmental management. Journal of Hospitality \& Tourism Research, 38(1), pp.95-115.

Pinto, L. and Allui, A., 2016. An analysis of drivers and barriers for sustainability supply chain management practices. Journal of Asia Entrepreneurship and Sustainability, 12(2), p.197.

Porter, M. E., \& Van der Linde, C. (1995). Toward a new conception of the environment-competitiveness relationship. Journal of economic perspectives, 9(4), pp.97-118

Prieto - Sandoval, V., Jaca, C., Santos, J., Baumgartner, R.J. and Ormazabal, M., 2019. Key strategies, resources, and capabilities for implementing circular economy in industrial small and medium enterprises. Corporate Social Responsibility and Environmental Management, 26(6), pp.1473-1484.

Roxas, B., Ashill, N. and Chadee, D., 2017. Effects of entrepreneurial and environmental sustainability orientations on firm performance: A study of small businesses in the Philippines. Journal of Small Business Management, 55, pp.163-178.

Seth, D., Rehman, M.A.A. and Shrivastava, R.L., 2018. Green manufacturing drivers and their relationships for small and medium (SME) and large industries. Journal of Cleaner Production, 198, pp.1381-1405.

Seth, D., Shrivastava, R.L. and Shrivastava, S., 2016. An empirical investigation of critical success factors and performance measures for green manufacturing in cement industry. Journal of Manufacturing Technology Management, 27(8), pp.1076-1101

Shashi, S., Cerchione, R., Centobelli, P. and Shabani, A., 2018. Sustainability orientation, supply chain integration, and SMEs performance: A causal analysis. Benchmarking: An International Journal, 25(9), pp.3679-3701.

Singh, N., Jain, S. and Sharma, P., 2014. Determinants of proactive environmental management practices in Indian firms: an empirical study. Journal of cleaner production, 66, pp.469-478.

Tachizawa, E.M., Gimenez, C. and Sierra, V., 2015. Green supply chain management approaches: drivers and performance implications. International Journal of Operations \& Production Management, 35(11), pp.15461566.

Tamayo-Orbegozo, U., Vicente-Molina, M.A. and Villarreal-Larrinaga, O., 2017. Eco-innovation strategic model. A multiple-case study from a highly eco-innovative European region. Journal of Cleaner Production, 142, pp.1347-1367. 
Testa, F., Boiral, O. and Iraldo, F., 2018. Internalization of environmental practices and institutional complexity: Can stakeholders pressures encourage greenwashing?. Journal of Business Ethics, 147(2), pp.287-307.

Thaib, D., 2020. Drivers of the green supply chain initiatives: Evidence from indonesian automotive industry. Uncertain Supply Chain Management, 8(1), pp.105-116.

Thurner, T.W. and Roud, V., 2016. Greening strategies in Russia's manufacturing-from compliance to opportunity. Journal of Cleaner Production, 112, pp.2851-2860.

Torkkeli, L., Uzhegova, M., Salojärvi, H., \& Saarenketo, S. (2017). Sustainability and Knowledge Dynamics in Entrepreneurial Growth: Evidence from Internationalizing Finnish SMEs. In Global Opportunities for Entrepreneurial Growth: Coopetition and Knowledge Dynamics within and across Firms. Emerald Publishing Limited, pp. 453-474

Tyler, B., Lahneman, B., Beukel, K., Cerrato, D., Minciullo, M., Spielmann, N. and Discua Cruz, A., 2020. SME managers' perceptions of competitive pressure and the adoption of environmental practices in fragmented industries: a multi-country study in the wine industry. Organization \& Environment, 33(3), pp.437-463.

Varadarajan, R., 2017. Innovating for sustainability: a framework for sustainable innovations and a model of sustainable innovations orientation. Journal of the Academy of Marketing Science, 45(1), pp.14-36.

Vilchez, V. F., Darnall, N., \& Correa, J. A. A. (2017). Stakeholder influences on the design of firms' environmental practices.

Vomberg, A., Homburg, C. and Bornemann, T., 2015. Talented people and strong brands: The contribution of human capital and brand equity to firm value. Strategic Management Journal, 36(13), pp.2122-2131.

Wang, F., Sun, J. and Liu, Y.S., 2019. Institutional pressure, ultimate ownership, and corporate carbon reduction engagement: Evidence from China. Journal of Business Research, 104, pp.14-26.

Wang, Z. and Sarkis, J., 2017. Corporate social responsibility governance, outcomes, and financial performance. Journal of Cleaner Production, 162, pp.1607-1616.

Weng, H.H.R., Chen, J.S. and Chen, P.C., 2015. Effects of green innovation on environmental and corporate performance: A stakeholder perspective. Sustainability, 7(5), pp.4997-5026.

Wiltshire, F. M. (1971). Department of Trade and Industry. Report of the Committee on Small Business, Australian Government Printing Service, Canberra.

Wolf, J., 2013. Improving the sustainable development of firms: The role of employees.

Business Strategy and the Environment, 22(2), pp.92-108.

Yin, C.Y., Du, F. and Chen, Y., 2020. Types of green practices, hotel price image and consumers' attitudes in China: The mediating role of consumer skepticism. Journal of Hospitality Marketing \& Management, 29(3), pp.329-357.

Yu, Y. and Huo, B., 2019. The impact of environmental orientation on supplier green management and financial performance: The moderating role of relational capital. Journal of cleaner production, 211, pp.628-639.

Zhang, H., \& Yang, F. (2016). On the drivers and performance outcomes of green practices adoption. Industrial Management \& Data Systems. 116(9), pp.2011-2034

Zhang, M., Tse, Y.K., Doherty, B., Li, S. and Akhtar, P., 2018. Sustainable supply chain management: Confirmation of a higher-order model. Resources, Conservation and Recycling, 128, pp.206-221. 